\title{
Do placental infarcts produce perinatal brain damage?
}

E. Jimenez, H. Hahm, R. Ferszt, R. Hohle, M. Vogel

\section{Introduction}

Routine morphological examination of 3500 human placentas annually and the autopsy findings in cases of perinatal cleath motivated us to investigate if defined plācental lesions produce perinatal brain damage. Several models for short-term perinatal asphyxia in rhesus-monkeys have been published $\therefore(1-4)$. However, animal models demonstrating the effect of defined placental infarction on the fetal brain are not available. Therefore we devised a method to produce placental infarcts experimentally.

\section{Miaterial and Method}

Wie injected a defined silicone mixture into one placenta of 49 pregnat guinea pigs, using the siblings as controls. At term, i.e. 2 hrs. to 27 days after injection, the fetuses were delivered by Cesarian section and placentas and brains examined by light microscopy. 43 fetuses showed placental lesions, 125 siblings served as controls.

\section{Results}

Those fetuses which survived placental infarcts of more than

6 hrs. duration and more than $30 \%$ of placental volume showed light microscopic changes in the brain: 
Age of placental lesion
Control fetus

no change

no change
$2-6$ hrs.

\section{7 hrs. to} several days karyopyknosis

of immature

glial cells

in $10 \%$ of
Fetus with placental lesion focal necroses of nerve cells and of Purkinje cells; karyopyknosis of immature glial cells; glial fatta metamorphosis;

perivascular edema.

2 - 4 weeks

no change

proliferation of immature glial cells; increased capillary density.

\section{Discussion}

Our results indicate that defined placental lesions reliably produce a lesional pattern in the fetal brain involving both immature neuronal and glial cells elements. While neuronal changes are plausible as acute hypoxic cell damage the glial lesions are remarkable and may provide a future model for fatty metamorphosis so well known in human fetal pathology. Chronic experiments now are under way to assure the functional importance of this lesional pattern for minimal brain damage.

\section{REFERENCES}

1. Ginsberg, M.D. and R.E. Meyers (1974).

2. Myers, R.E. (1975). Biol. Neonate 26, 21-43.

3. Sumi, S.M. (1974) Arch. Neurol. 31, 38-44.

4. Windle, W.F. (1963). Science 140, 1186-1189.

Dr.E.Jimenez, Abt.f.Paidopathologie und Plazentologie, Inst.f. Pathologie im Klinikum Charlottenburg der FUB, Spandauer Damm 130, D-1000 Berlin 19 